Research Article

\title{
Impact of High Temperature on the Compressive Strength of ECC
}

\author{
Xingyan Shang and Zhoudao Lu \\ College of Civil Engineering, Tongji University, Shanghai 200092, China \\ Correspondence should be addressed to Zhoudao Lu; lzd@tongji.edu.cn
}

Received 20 January 2014; Accepted 13 June 2014; Published 25 June 2014

Academic Editor: Osman Gencel

Copyright (C) 2014 X. Shang and Z. Lu. This is an open access article distributed under the Creative Commons Attribution License, which permits unrestricted use, distribution, and reproduction in any medium, provided the original work is properly cited.

\begin{abstract}
The influence of different cooling regimes (quenching in water and cooling in air) on the residual mechanical properties of ECC (engineered cementitious composites) exposed to high temperature up to $800^{\circ} \mathrm{C}$ was discussed in this paper. The specimens quenching in water gained better mechanical properties than the ones cooling in air. The strengthening effect of quenching for specimens subjected to $800^{\circ} \mathrm{C}$ was more significant than for the ones subjected to $400^{\circ} \mathrm{C}$. The microstructural characterization is examined before and after exposure to fire deterioration by using scanning electron microscopy. Results from the microtest well explained the mechanical properties variation of postfire specimens.
\end{abstract}

\section{Introduction}

Concrete is the most widely used construction material in the world. Although it was primarily designed for carrying compressive loads, concrete in real field conditions is also subjected to tensile stresses because of structural loading, shrinkage (if the shrinkage is restrained), chemical attack, and thermal deformations. The tensile strength of concrete is only approximately $10 \%$ of its compressive strength, and brittle concrete cracks when subjected to tensile stresses. In recent years, the effort to modify the brittle nature of ordinary concrete has resulted in modern concepts of ultrahigh performance fiber-reinforced cementitious composites (UHPFRCC), which are characterized by tensile strain-hardening after first cracking. Depending on its composition, its tensile strain capacity can be up to several hundred times those of normal and fiber-reinforced concrete. ECC is a special type of UHP-FRCC designed based on micromechanical principles to strain-harden in tension. It offers high ductility under uniaxial tensile loading and improved durability due to an intrinsically tight crack width of less than $100 \mu \mathrm{m}[1,2]$. During the last decade, the use of ECC has considerably grown up, and it was used in a variety of structures in various regions $[3,4]$.

Significant attention has been brought to the study of its rheological, mechanical, and durability related properties of ECC. With an increase in the application of ECC, the risk of exposure to elevated temperatures increases as well. The behavior of ECC exposed to high temperature has to be evaluated in particular.

For normal cement based composite, high temperatures caused physical and chemical changes, resulting in its mechanical property deterioration, such as compressive strength and modulus of elasticity. Different cooling regimes, that is, cooling in air, quenching in water, or water spraying, also had a significant influence on the residual mechanical properties of postfire composite [5,6]. Gencel [7] researched the effect of heating duration and cooling regimes on mechanical properties of high strength concrete containing different proportions of hematite. Researchers [8] studied the mechanical and physical properties of lightweight concrete after high temperature. The residual properties of ECC after exposure to high temperatures have also been studied by several researchers, mainly on the heating temperatures and mineral admixtures of fly ash and fiber influence $[9,10]$. But there are still some aspects remaining to be studied. The main objective of this research is to gain a better understanding of the influence of cooling regimes on the postfire ECC specimens subjected to high temperature up to $800^{\circ} \mathrm{C}$.

\section{Experimental Studies}

2.1. Materials, Mix Proportions, and Basic Mechanical Properties. The materials used in the production of ECC mixture 
TABLE 1: Mixture properties of ECC.

\begin{tabular}{lc}
\hline & ECC \\
\hline Cement $(\mathrm{C})\left(\mathrm{kg} / \mathrm{m}^{3}\right)$ & 650 \\
Fly ash $(\mathrm{FA})\left(\mathrm{kg} / \mathrm{m}^{3}\right)$ & 325 \\
Water $(\mathrm{W})\left(\mathrm{kg} / \mathrm{m}^{3}\right)$ & 375 \\
PVA fiber $\left(\mathrm{kg} / \mathrm{m}^{3}\right)$ & 26 \\
Sand $\left(\mathrm{kg} / \mathrm{m}^{3}\right)$ & 480 \\
HRWR $\left(\mathrm{kg} / \mathrm{m}^{3}\right)$ & 12 \\
HPMC $\left(\mathrm{kg} / \mathrm{m}^{3}\right)$ & 1.90 \\
W/(C $+\mathrm{FA})$ & 0.38 \\
FA/C & $50 \%$ \\
\hline
\end{tabular}

were Type I Portland cement (C), Class F fly ash (FA), sand, water, polyvinyl alcohol (PVA) fibers, a polycarboxylic ether type high-range water-reducing admixture (HRWR), and hydroxypropyl methylcellulose (HPMC). The mix details are given in Table 1. Unlike typical fiber-reinforced cementitious composites, the component characteristics and proportions within the ECC are carefully determined with the use of micromechanical design tools to achieve the desired strainhardening response $[11,12]$. The PVA fibers with a diameter of $39 \mu \mathrm{m}$ and a length of $8 \mathrm{~mm}$ are purposely manufactured with a tensile strength $(1620 \mathrm{MPa})$, elastic modulus $(42.8 \mathrm{GPa})$, and maximum elongation (6.0\%) matching those needed for strain-hardening performance. Additionally, the surface of the PVA fibers is coated with a proprietary oiling agent $1.2 \%$ by mass to tailor the interfacial properties between fiber and matrix for strain-hardening performance [11].

To characterize the direct tensile behavior of the ECC mixtures, the dog-bone specimens were used. Direct tensile tests [13] were conducted under displacement control at a loading rate of $0.005 \mathrm{~mm} / \mathrm{s}$. The typical tensile stress-strain curves of the ECC mixtures at 28 days are shown in Figure 1. The ECC composites exhibited a strain capacity of $4.4 \%$ at 28 days, with an ultimate strength of about $5 \mathrm{MPa}$.

\subsection{Test Specimen Preparation and Testing. Specimens were} removed from the molds at 1 day and kept in a water tank until the age of 28 days. Five specimens were tested under compression immediately after conditioning; these control specimens will be referred to as those tested after exposure to normal curing condition (unheated).

Computer controlled furnace was used for the heating of specimens with constant heating rate of about $13.3^{\circ} \mathrm{C} / \mathrm{min}$ to reach the prescribed $200,400,600$, and $800^{\circ} \mathrm{C}$ temperature levels. The temperature was measured in the air at a position above the specimen inside the furnace. The temperature was maintained constant for an hour to achieve the thermal steady state condition after the target temperature was reached. It was expected that because of small size of specimens used in this study, the temperature in the center of the specimen reached the target temperature during the one-hour stabilization phase. The heating regime is shown in Figure 2. After heating, the samples were subjected to two cooling regimes as given in Table 2. After cooling, the specimens were sealed for 7 days before the compressive test. The compressive test [14] was performed under displacement control at a loading rate
TABLE 2: Two cooling regimes for different curing age ECC specimens.

\begin{tabular}{lcc}
\hline Temperature & Cooling in room temperature & Quenching in water \\
\hline $200^{\circ} \mathrm{C}$ & $\sqrt{ }$ & None \\
$400^{\circ} \mathrm{C}$ & $\sqrt{ }$ & $\sqrt{ }$ \\
$600^{\circ} \mathrm{C}$ & $\sqrt{ }$ & None \\
$800^{\circ} \mathrm{C}$ & $\sqrt{ }$ & $\sqrt{ }$ \\
\hline
\end{tabular}

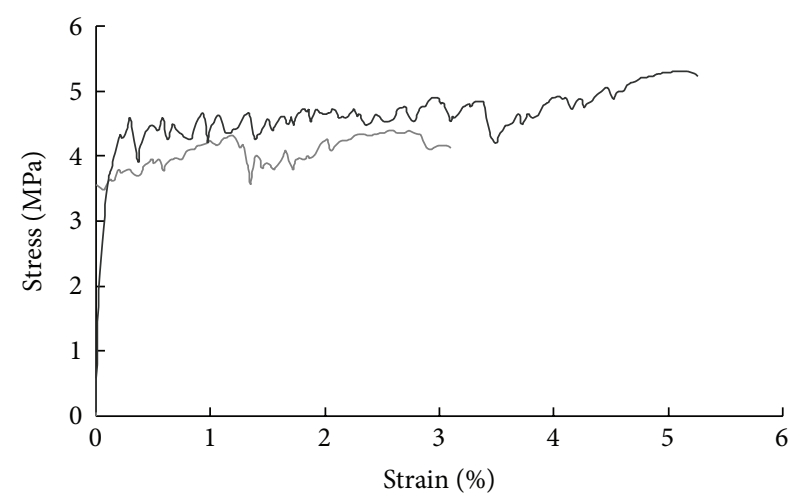

FIGURE 1: Typical tensile stress-strain response of ECC at 28 days.

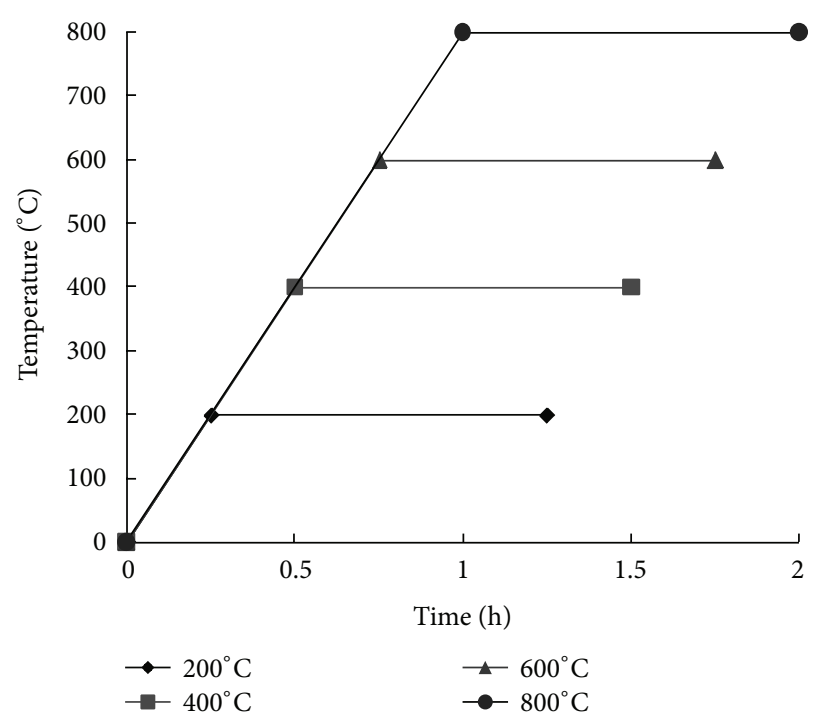

FIGURE 2: Heating regime for ECC specimens.

of $0.005 \mathrm{~mm} / \mathrm{s}$ on a closed-loop controlled material testing system with $100 \mathrm{kN}$ capacity. During the compressive tests, the load and the deflection values (obtained from a pair of LVDT's attached to the test set-up) were recorded on a computerized data acquisition system. Four samples were tested for each heating temperature and cooling regime.

The specimens are named as follows: temperaturecooling regime, for example, $400 \mathrm{~A}(\mathrm{~W})$; here A means cooling in air and $\mathrm{W}$ means cooling in water for 5 minutes. The weight of each specimen was also measured before and after exposure to calculate the mass loss of fire-deteriorated specimens. 


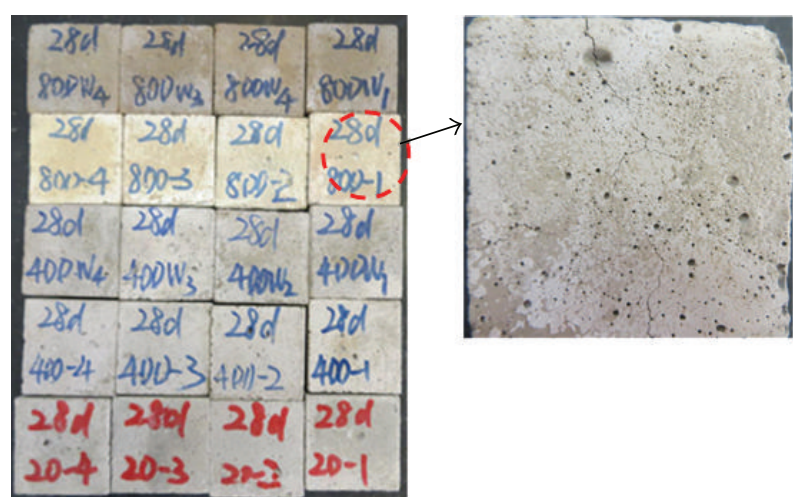

FIGURE 3: Color changes and surface cracks of postfire specimens.

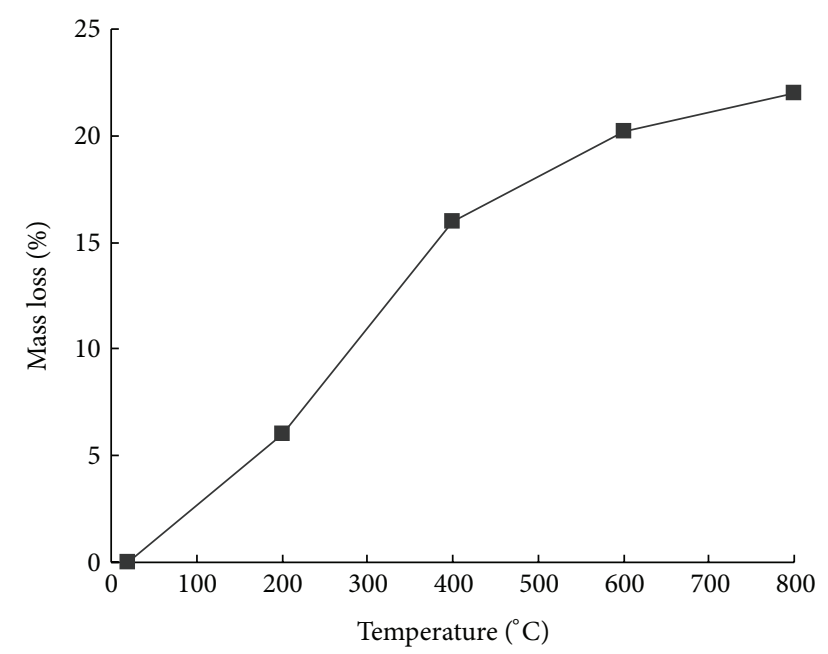

FIgURE 4: Mass loss of specimens of all curing ages with temperatures.

\section{Experimental Results and Discussions}

3.1. Surface and Internal Characteristics. It is observed that when the ECC specimens were exposed to high temperatures, some changes in color occurred. Figure 3 shows that the color of ECC specimens changed from gray at $20^{\circ} \mathrm{C}$ to light yellow at $800^{\circ} \mathrm{C}$ due to the loss of water and chemical decomposition. The specimens are small and we cannot write many words on them, so the specimens with "W" mean cooling in water and without "W" mean cooling in air. The color of the specimens subjected to $800^{\circ} \mathrm{C}$ and then quenching in water turned to dark gray which may be due to the further hydration of the composite.

Surface crack patterns of ECC specimens due to the high temperature exposure were almost the same up to $800^{\circ} \mathrm{C}$. Cracks became apparent after $400^{\circ} \mathrm{C}$, and hairline cracks were monitored above $400^{\circ} \mathrm{C}$. Increasing the exposure temperature to $800^{\circ} \mathrm{C}$ increased the size of microcracking as consistent with pore structure variation of the specimens. However, quenching in the water may help to heal the surface crack due to the further hydration.

3.2. Mass Loss. The deterioration of specimens subjected to various elevated temperatures was also assessed by mass loss measurements. Figure 4 shows the relation between mass loss $\left(M_{0}-M_{i}\right) / M_{0}$ (in percentage) and temperature of heatexposed ECC. $M_{i}$ is the mass after a specific thermal heat exposure, and $M_{0}$ is initial mass, prior to heat exposure. As seen in Figure 4, the mass loss increased with the increasing temperature of thermal exposure, a result mainly associated with the liberation of free and physically bound water. At higher temperatures of 600 and $800^{\circ} \mathrm{C}$, the weight change of ECC was caused by the dehydration of paste [15]. During a heat treatment up to $400^{\circ} \mathrm{C}$, the weight of the melted fibers also had an influence on mass loss.

3.3. Microstructure Characterization by Using SEM Observations. The microstructure of specimens was investigated using scanning electron microscope (SEM) observation. The results of the microscopic investigations gave a good explanation of the change in macrobehavior of ECC in comparison to ECC matrix mixtures.

To study the behavior of fibers and matrix microstructure after various elevated temperatures, observations with an SEM were performed on samples taken from the core of postfire ECC specimens that had been exposed to a temperature between 200 and $800^{\circ} \mathrm{C}$ for one hour. The specimens that had been quenched in the water for 5 minutes were also observed. Figure 5 shows the SEM micrographs of various postfire ECC specimens exposed to different heating temperature and cooling regimens. Figures 5(a) and 5(b) show the SEM micrographs of ECC specimens for $200 \mathrm{~A}$ and $400 \mathrm{~A}$. The fiber did not melt when the specimens were subjected to $200^{\circ} \mathrm{C}$. After exposure to $400^{\circ} \mathrm{C}$, PVA fibers melt completely, creating additional interconnected pores and small channels in the matrix, and fibers alone constitute a connected net work. Therefore, the use of PVA fiber clearly affects porosity at high temperatures. After exposure to $400^{\circ} \mathrm{C}$, the number and width of microcracks increase obviously compared to specimens subjected to $200^{\circ} \mathrm{C}$ from the SEM observation. From Figure 5(c), it can be seen that the hydration products did not decompose totally. For the specimens exposure to $800^{\circ} \mathrm{C}$ (Figure $5(\mathrm{~d})$ ), almost all hydration products appear as ill-crystallized or amorphous structures by losing the characteristic crystal structure. From Figures 5(e) and 5(f), we can see the typical crystal structure of specimens quenching in water and curing for 7 days. The produce of new crystal enhances the strength of specimens which would be discussed in the following section. Additionally, there are more new generated crystals in $800 \mathrm{~W}$ specimens than in $400 \mathrm{~W}$ specimens, which results in a more significant mechanical increase in $800 \mathrm{~W}$ specimens.

\subsection{Residual Compressive Strength and Stress-Strain Curves.} Figure 6 shows the influence of temperature on the compressive strength and stiffness of postfire ECC specimens. Relative strength, stiffness, and displacement were the ratios of the strength, stiffness, and displacement of specimens after high temperature to those of the control (unheated) specimens. Each point in Figure 6 was obtained from the average of at least four test specimens. The coefficient of variance (COV) values for the compressive strength values ranged from $2 \%$ to $9 \%$. The narrow range of COV values is an indication of the consistent repeatability of the compressive strength test method even for fire-deteriorated specimens. 


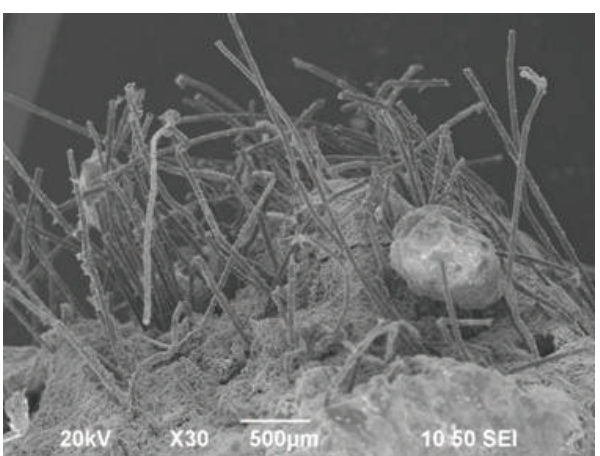

(a) $200 \mathrm{~A}$

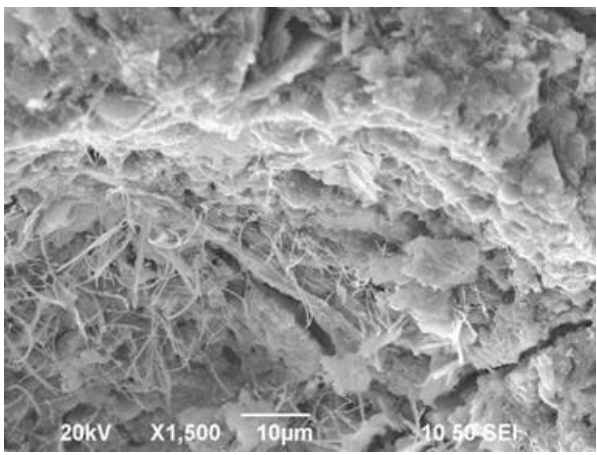

(c) $600 \mathrm{~A}$

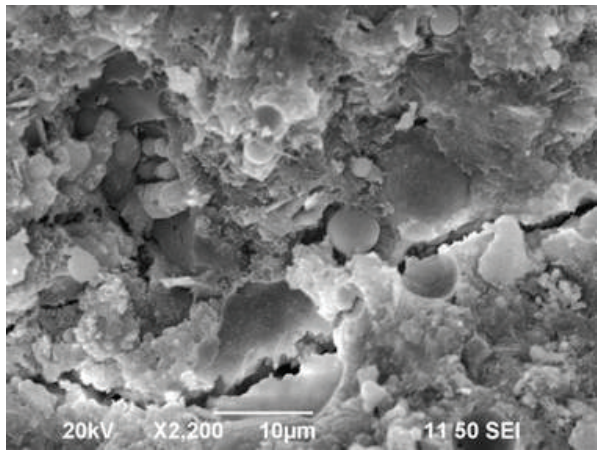

(e) $400 \mathrm{~W}$

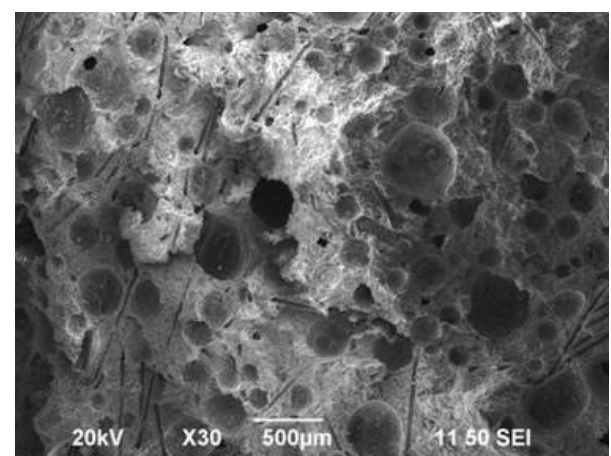

(b) $400 \mathrm{~A}$

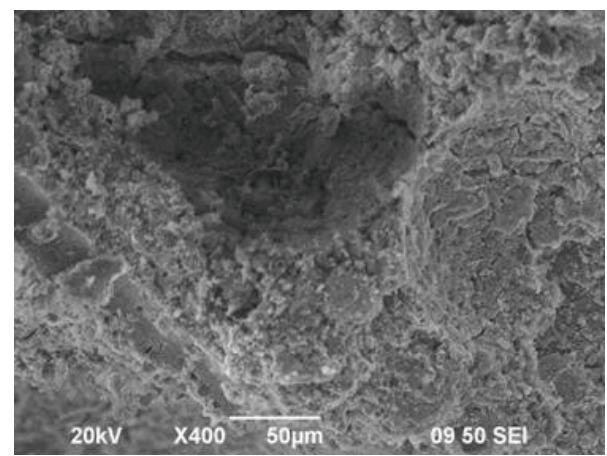

(d) $800 \mathrm{~A}$

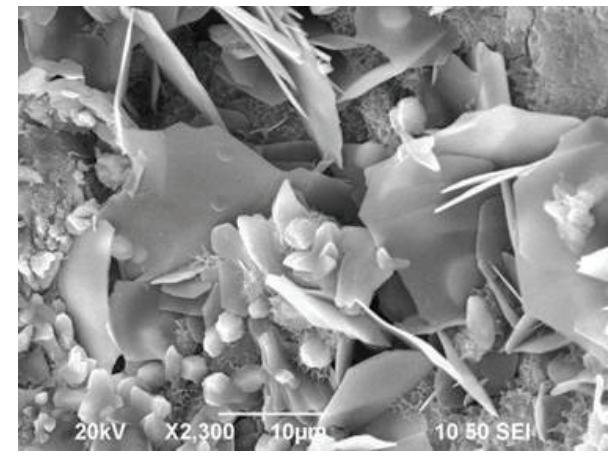

(f) $800 \mathrm{~W}$

FIGURE 5: SEM micrograph of ECC specimens subjected to different heating temperatures and cooling regimes.

As seen in Figure 6 and as expected, exposure to high temperature influenced the residual compressive strength of ECC specimens substantially. However, percent variation in compressive strength can be classified in four distinct patterns of strength loss, $23-200^{\circ} \mathrm{C}, 200-400^{\circ} \mathrm{C}, 400-600^{\circ} \mathrm{C}$, and $600-800^{\circ} \mathrm{C}$. Temperature no more than $200^{\circ} \mathrm{C}$ seems to help the strength increase. Mean compressive strength of 28 -day ECC specimens increases by $1 \%$ after exposure to $200^{\circ} \mathrm{C}$. The influence of high temperature exposure on the residual compressive strength is not prominent up to $400^{\circ} \mathrm{C}$ with the mean compressive strength decreased by $32 \%$ after exposure to $400^{\circ} \mathrm{C}$. This might be due to the less sensitivity of compressive strength to minor microcracks. Heating up to $400^{\circ} \mathrm{C}$ generated a relatively small amount of cracking, which did not cause any immediate loss of carrying capacity in compression because the slightly cracked concrete could work as a highly redundant structure [12]. Beyond $400^{\circ} \mathrm{C}$, however, compressive strength dropped drastically by $62 \%$ and $77 \%$ at $600^{\circ} \mathrm{C}$ and $800^{\circ} \mathrm{C}$, respectively. According to the variation of the residual compressive strength, temperature of $600^{\circ} \mathrm{C}$ and above might be regarded as critical temperature range for the strength loss of ECC. The present test results are in line with the findings of previous studies $[9,10]$.

Residual compressive strength variations are consistent with the pore structure variations in previous studies $[16,17]$. The total intruded porosity and percent of pore size between $50 \mathrm{~nm}$ and $500 \mathrm{~nm}$ increased slightly with the increase in temperature up to $400^{\circ} \mathrm{C}$. The increase in porosity up to $400^{\circ} \mathrm{C}$ is most likely due to the small channels created in ECC by melting PVA fibers with the diameter of $39 \mu \mathrm{m}$. However, after exposure to $600^{\circ} \mathrm{C}$, the main causes of deterioration in compressive strength might be attributed both to the physical transformation of the matrix and to chemical transformation of hydration products. When the temperature was raised 


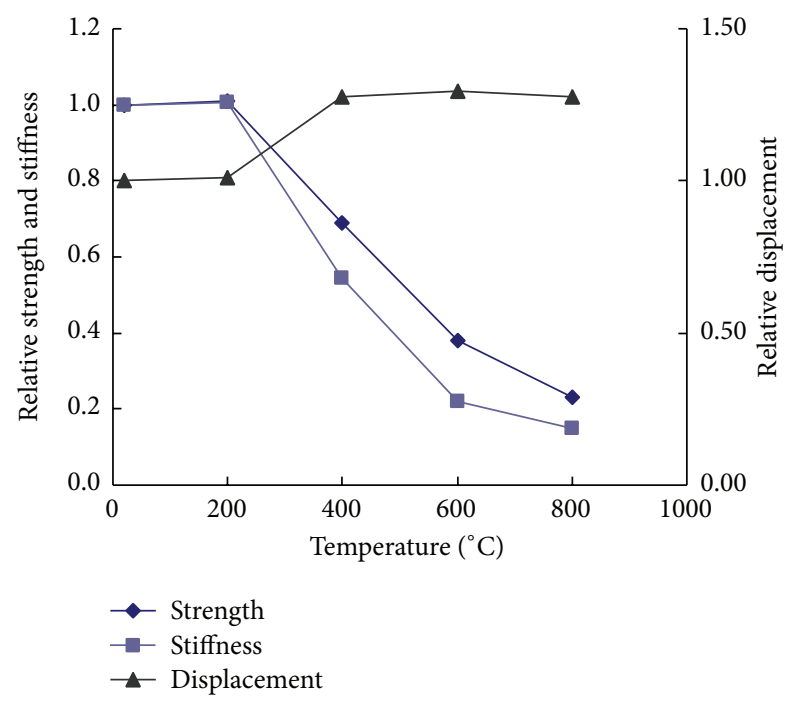

FIGURE 6: Compressive strength, stiffness, and displacement corresponding to peak load with temperatures.

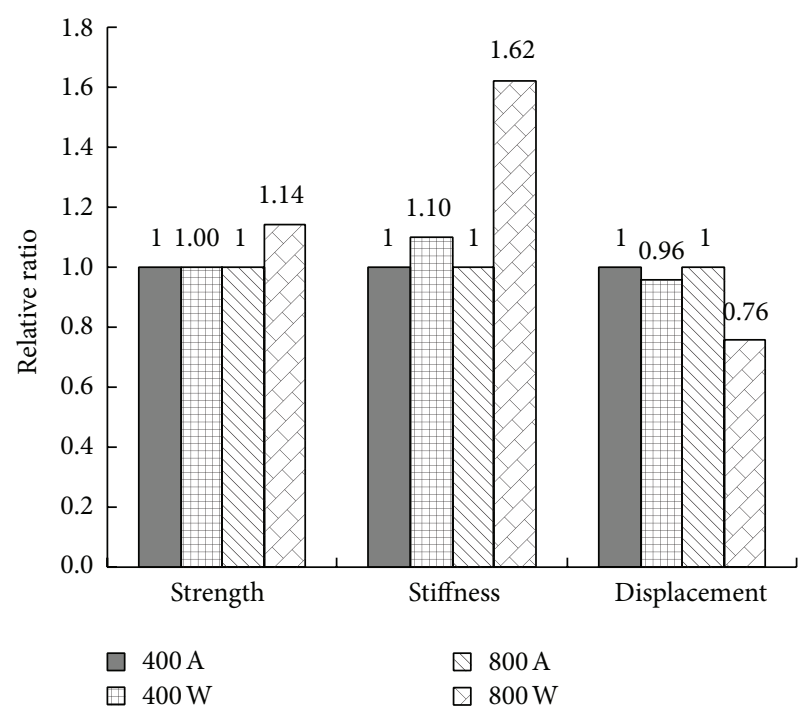

FIGURE 7: Influence of cooling regimes on compressive strength, stiffness, and displacement corresponding to peak load.

to $600^{\circ} \mathrm{C}$, decomposition of the major hydrate, known as tobermorite (gel), was inevitable [18], causing severe increase in the microstructure of its matrix and the loss of binder property.

From Figure 6, it can be seen that the stiffness of postfire specimens shares a similar but more sensitive tendency $[19,20]$ with exposure temperatures, which also could be classified into four stages. The mean compressive stiffness of ECC specimens increased by $0.5 \%$ after exposure to $200^{\circ} \mathrm{C}$, while it decreased by $46 \%, 78 \%$, and $85 \%$ after exposure to 400,600 , and $800^{\circ} \mathrm{C}$.

Figure 7 shows the influence of cooling regimes on the residual mechanical properties. Relative strength, stiffness, and displacement were the ratios of the strength, stiffness, and displacement of specimens cooling in water to those of the specimens cooling in air. For the specimens subjected

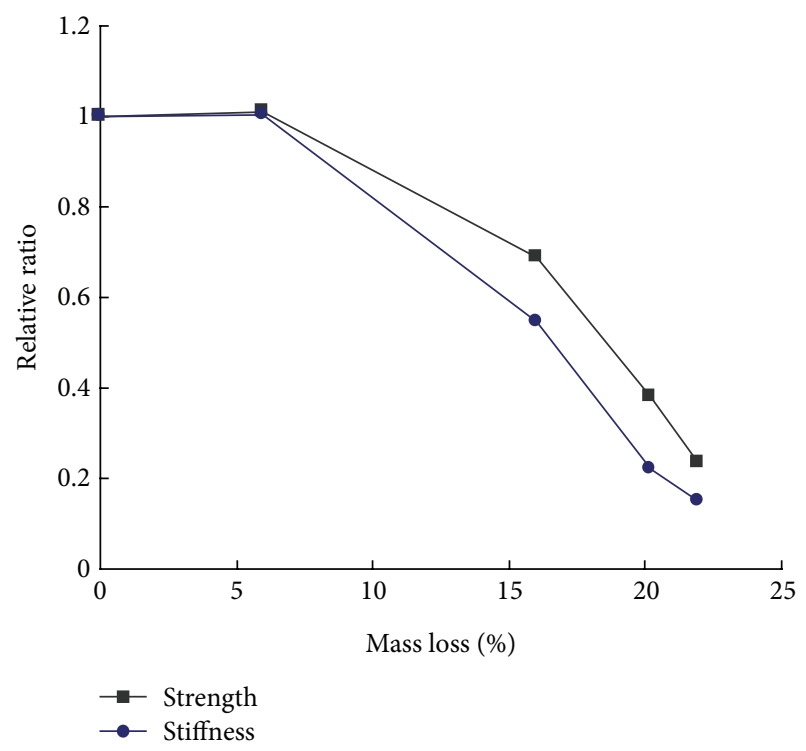

FIGURE 8: Relationship of strength and stiffness to mass loss.

to heating temperature of $400^{\circ} \mathrm{C}$, the compressive strength and stiffness of specimens quenching in water increased by $0.5 \%$ and $14 \%$ compared to the ones cooling in air, while, for $800^{\circ} \mathrm{C}$, the compressive strength and stiffness of specimens quenching in water were 1.10 and 1.62 times to the ones cooling in air. As mentioned in Section 3.3, there are more new generated crystals in $800 \mathrm{~W}$ specimens than in $400 \mathrm{~W}$ specimens, which results in a more significant mechanical increase in $800 \mathrm{~W}$ specimens. The result again shows that the stiffness is more sensitive than strength to microcracks, which could also be seen from the result of Figure 8 . The meaning of relative ratio is the same with that in Figure 6. Meanwhile, the displacement corresponding to the peak load of $400 \mathrm{~W}$ and $800 \mathrm{~W}$ decreased by $4 \%$ and $24 \%$ compared to the specimens cooling in air.

The stress-strain curves of ECC specimens at room temperature and elevated temperatures are compared in Figure 9. Ultimate stress decreased with the increasing temperature, particularly for temperatures exceeding $400^{\circ} \mathrm{C}$, while the strain corresponding to the peak strength increased with temperature. The slope decreased with the increase in exposure temperature up to $800^{\circ} \mathrm{C}$, indicating a reduction in the stiffness of the ECC. The reduction in ECC stiffness was relatively low up to $400^{\circ} \mathrm{C}$; however, beyond $400^{\circ} \mathrm{C}$, a dramatic reduction was monitored in the ECC stiffness. As expected, with the increase in exposure temperature, the postpeak stress of the ECC specimens dropped faster, resulting in a smaller postpeak area under the curve. This behavior becomes more evident when the exposure temperature level reaches $800^{\circ} \mathrm{C}$ : ECC specimens failed soon after reaching their peak strength. This means that increasing the exposed temperature level tends the ductile nature of ECC to brittle nature.

\section{Conclusions}

The influence of cooling regimes on the mechanical properties of ECC specimens subjected to elevated temperatures was 


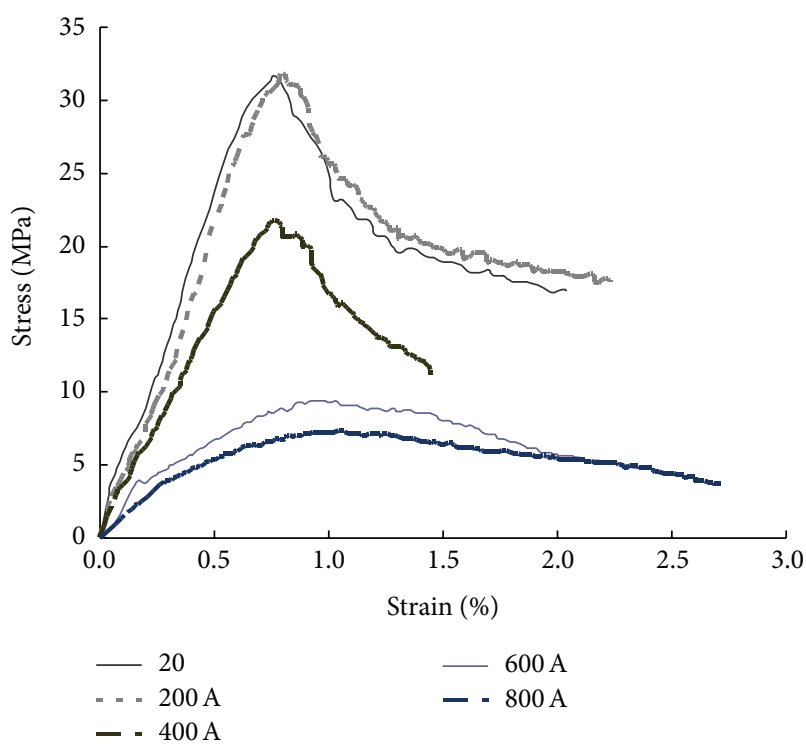

(a) Postfire specimens cooling in the air

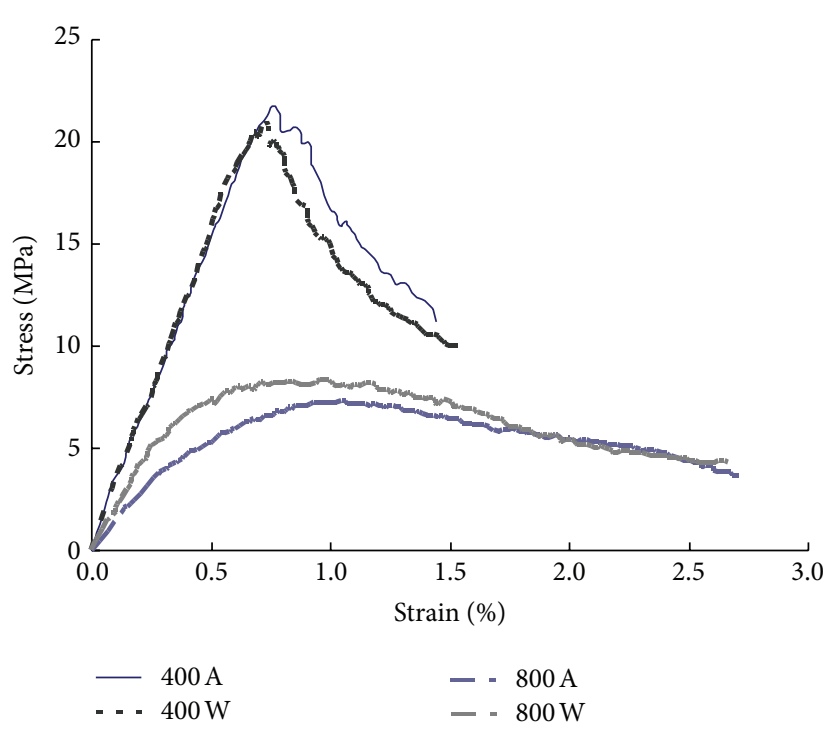

(b) Stress-strain curve of specimens subjected to different cooling regimes

FIGURE 9: Stress-strain curves of ECC specimens for different curing ages.

investigated in this paper and the following conclusions can be drawn.

(1) The color of ECC specimens changed from gray at $20^{\circ} \mathrm{C}$ to light yellow at $800^{\circ} \mathrm{C}$; the specimens quenching in water turned to dark grey. Hairline cracks were monitored above $400^{\circ} \mathrm{C}$ and quenching in the water helps to heal the surface crack. The mass loss increased with the increasing temperature of thermal exposure.

(2) The compressive strength can be classified into four distinct patterns of strength loss: $23-200^{\circ} \mathrm{C}$, $200-400^{\circ} \mathrm{C}, 400-600^{\circ} \mathrm{C}$, and $600-800^{\circ} \mathrm{C}$. From 23 to $200^{\circ} \mathrm{C}$, the compressive strength of specimens increases with temperature. The influence of high temperature exposure on the residual compressive strength is not prominent up to $400^{\circ} \mathrm{C}$. Beyond $600^{\circ} \mathrm{C}$, ECC specimens showed severe deterioration.

(3) The cooling regime of quenching in water helped the strength and stiffness recovery. Ultimate stress decreases with the increasing temperature, while the strain corresponding to the peak strength increases with temperature. High temperature causes a reduction in the stiffness of ECC. Increasing the exposed temperature level tends the ductile nature of ECC to brittle nature.

\section{Conflict of Interests}

The authors declare that there is no conflict of interests regarding the publication of this paper.

\section{Acknowledgment}

The authors gratefully acknowledge the financial assistance of the National Science Foundation of China (51378397).

\section{References}

[1] V. C. Li, "ECC—-tailored composites through micromechanical modeling," in Proceedings of the Fiber Reinforced Concrete: Present and the Future Conference, N. Banthia, Ed., pp. 64-97, CSCE Press, 1998.

[2] V. C. $\mathrm{Li}$, "On engineered cementitious composites (ECC)A review of the material and its applications," Journal of Advanced Concrete Technology, vol. 1, no. 3, pp. 215-230, 2003.

[3] M. Şahmaran and V. C. Li, "De-icing salt scaling resistance of mechanically loaded engineered cementitious composites," Cement and Concrete Research, vol. 37, no. 7, pp. 1035-1046, 2007.

[4] M. Sahmaran, M. Li, and V. C. Li, "Transport properties of engineered cementitious composites under chloride exposure," ACI Materials Journal, vol. 104, no. 6, pp. 604-611, 2007.

[5] X. Luo, W. Sun, and S. Y. N. Chan, "Effect of heating and cooling regimes on residual strength and microstructure of normal strength and high-performance concrete," Cement and Concrete Research, vol. 30, no. 3, pp. 379-383, 2000.

[6] G. F. Peng, S. H. Bian, Z. Q. Guo, J. Zhao, X. Peng, and Y. Jiang, "Effect of thermal shock due to rapid cooling on residual mechanical properties of fiber concrete exposed to high temperatures," Construction and Building Materials, vol. 22, no. 5, pp. 948-955, 2008.

[7] O. Gencel, "Effect of elevated temperatures on mechanical properties of high-strength concrete containing varying proportions of hematite," Fire and Materials, vol. 36, no. 3, pp. 217-230, 2012.

[8] F. Koksal, O. Gencel, W. Brostow, and H. E. Hagg Lobland, "Effect of high temperature on mechanical and physical properties of lightweight cement based refractory including expanded 
vermiculite," Materials Research Innovations, vol. 16, no. 1, pp. 7-13, 2012.

[9] M. Sahmaran, M. Lachemi, and V. C. Li, "Assessing mechanical properties and microstructure of fire-damaged engineered cementitious composites," ACI Materials Journal, vol. 107, no. 3, pp. 297-304, 2010.

[10] M. Şahmaran, E. Özbay, H. E. Yücel, M. Lachemi, and V. C. Li, "Effect of fly ash and PVA fiber on microstructural damage and residual properties of engineered cementitious composites exposed to high temperatures," Journal of Materials in Civil Engineering, vol. 23, no. 12, pp. 1735-1745, 2011.

[11] V. C. Li, C. Wu, S. Wang, A. Ogawa, and T. Saito, "Interface tailoring for strain-hardening polyvinyl alcohol-engineered cementitious composite (PVA-ECC)," ACI Materials Journal, vol. 99, no. 5, pp. 463-472, 2002.

[12] T. T. C. Hsu, F. O. Slate, G. M. Sturman, and G. Winter, "Microcracking of plain concrete and the shape of the stressstrain curve," ACI Mater, vol. 60, no. 2, pp. 209-224, 1963.

[13] Japan Society of Civil Engineers, Recommendations for Design and Construction of High Performance Fiber Reinforced Cement Composite with Multiple Fine Cracks, (Japanese).

[14] ASTM C109/C109M-12, "Standard test method for compressive strength of hydraulic cement mortars (using 2-in. or [50-mm] cube specimens)".

[15] H. F. W. Taylor, The Chemistry of Cements, Academic Press, London, UK, 1964.

[16] T. K. Erdem, "Specimen size effect on the residual properties of engineered cementitious composites subjected to high temperatures," Cement and Concrete Composites, vol. 45, pp. 1-8, 2014.

[17] Y. N. Chan, X. Luo, and W. Sun, "Compressive strength and pore structure of high-performance concrete after exposure to high temperature up to $800^{\circ} \mathrm{C}$," Cement and Concrete Research, vol. 30, no. 2, pp. 247-251, 2000.

[18] G. A. Khoury, B. N. Grainger, and P. J. E. Sullivan, "Transient thermal strain of concrete: literature review, conditions within specimen and behavior of individual constituents," Magazine of Concrete Research, vol. 37, no. 132, pp. 131-144, 1985.

[19] Y. Xu, Y. L. Wong, C. S. Poon, and M. Anson, "Influence of PFA on cracking of concrete and cement paste after exposure to high temperatures," Cement and Concrete Research, vol. 33, no. 12, pp. 2009-2016, 2003.

[20] B. Wu, X. Su, H. Li, and J. Yuan, "Effect of high temperature on residual mechanical properties of confined and unconfined high-strength concrete," ACI Materials Journal, vol. 99, no. 4, pp. 399-407, 2002. 

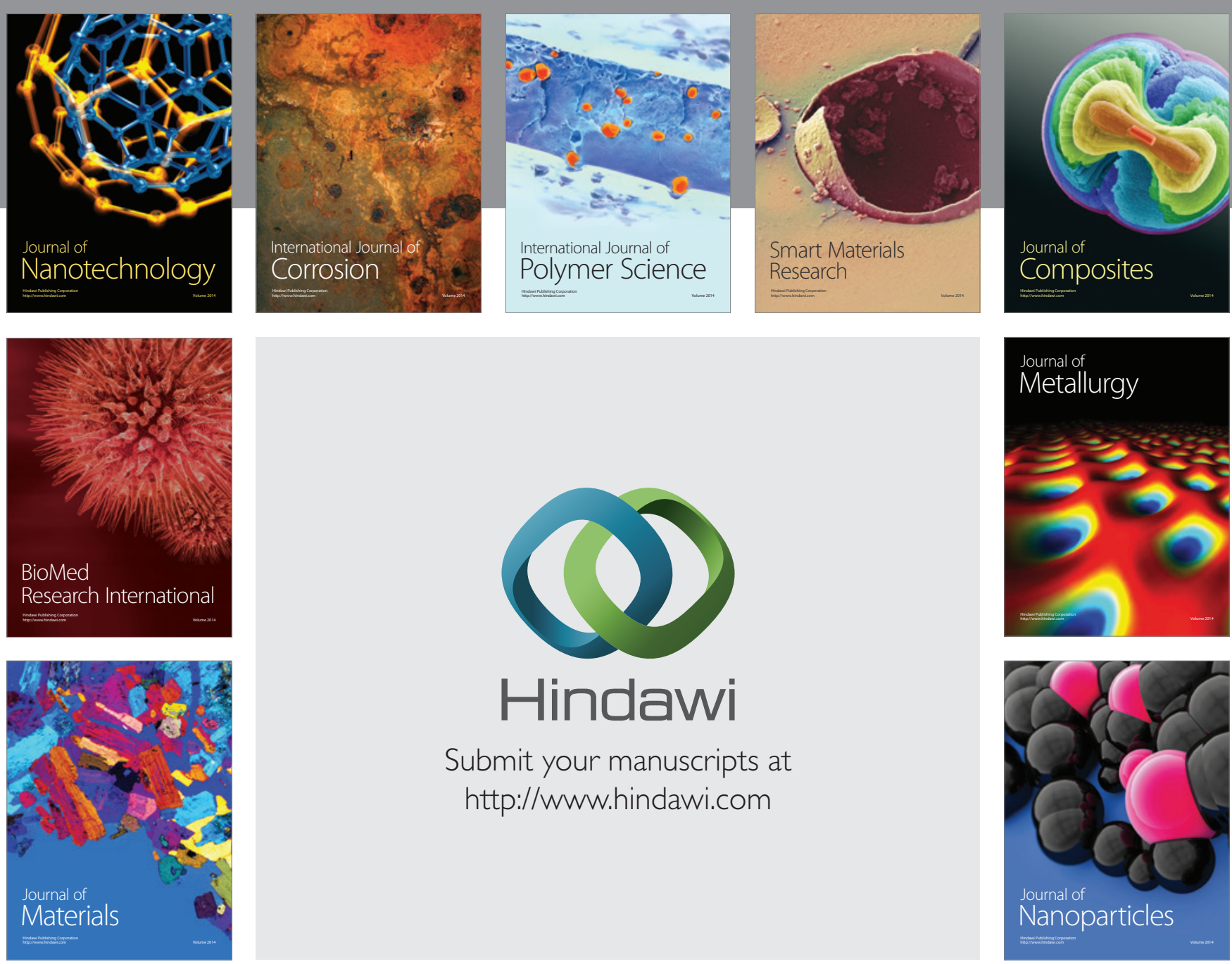

Submit your manuscripts at http://www.hindawi.com
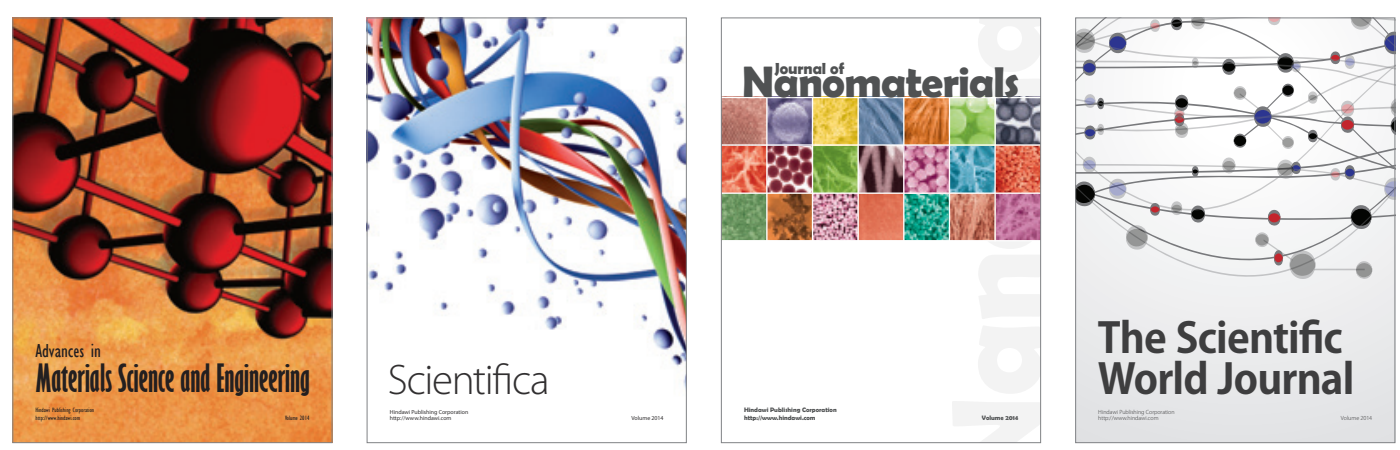

\section{The Scientific World Journal}
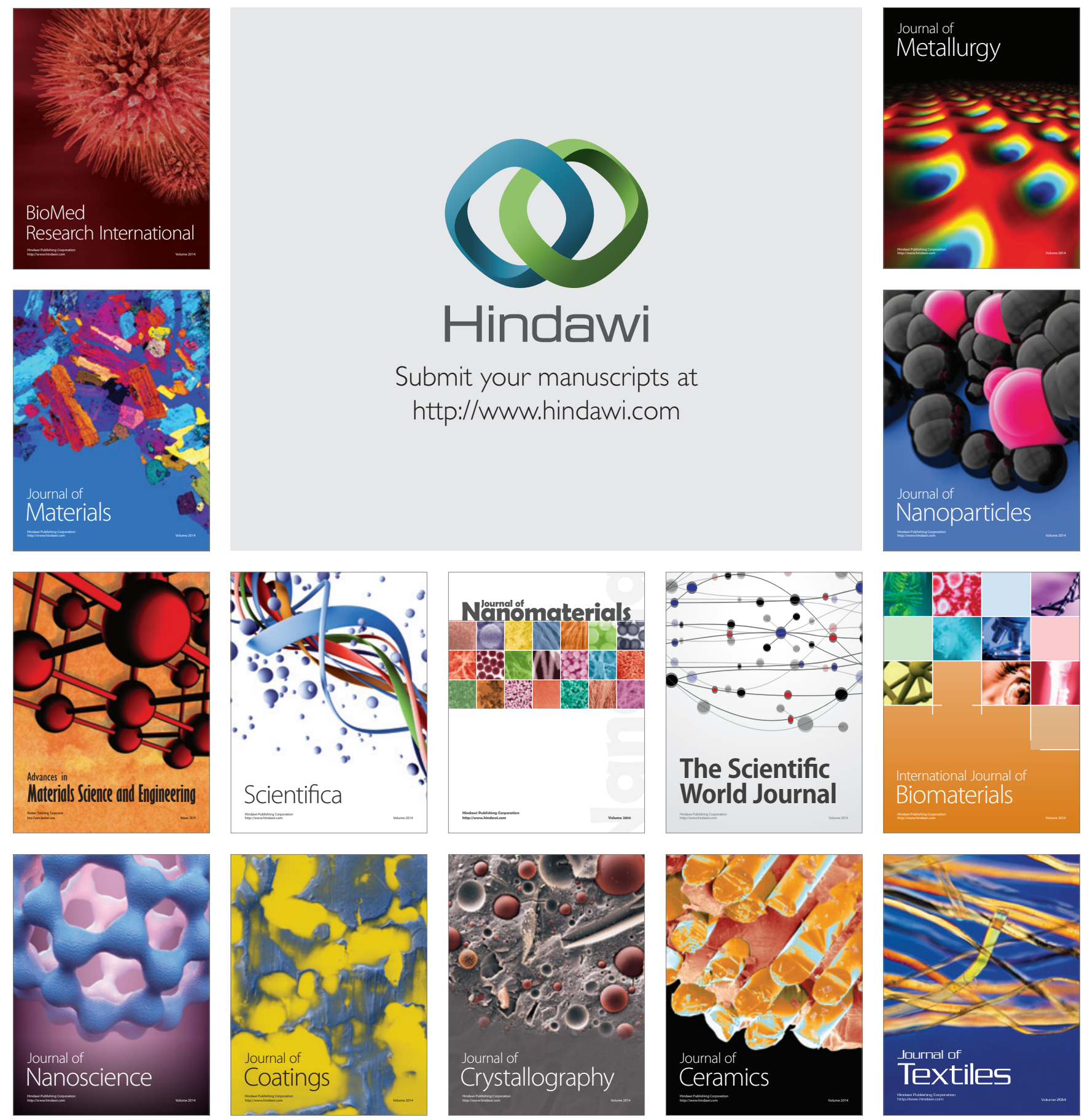